\title{
REQUISITOS-CHAVE DAS MICRO E PEQUENAS EMPRESAS INOVADORAS: A EXPERIÊNCIA DE CAMPO DE AGENTES LOCAIS DE INOVAÇÃO
}

\author{
KEY REQUIREMENTS OF INNOVATIVE SMALL BUSINESSES: LOCAL INNOVATION AGENTS' \\ EXPERIENCE IN THE FIELD
}

\section{REQUISITOS LLAVE DE LAS MICRO Y PEQUEÑAS EMPRESAS INNOVADORAS: LA EXPERIENCIA DE CAMPO DE AGENTES LOCALES DE INNOVACIÓN}

\author{
LUCIANA GRACI RODELA \\ Doutora \\ Universidade de São Paulo - Brasil \\ luciana.rodela@gmail.com \\ Submetido em: 05/10/2017 \\ Aprovado em: 05/03/2018 \\ Doi: alcance.v24n4(Out/Dez).p476-494
}

\begin{abstract}
RESUMO
O objetivo deste trabalho é indicar e discutir quais fundamentos práticos fazem com que as micro e pequenas empresas (MPE) sejam inovadoras, fortalecidas e atuais. A discussão teve como base a experiência de campo de 18 agentes locais de inovação, profissionais capacitados pelo SEBRAE, bolsistas do CNPq, que acompanharam mensalmente, por dois anos, um total inicial de 784 MPE do estado de São Paulo. Os agentes realizaram diagnósticos da gestão e da inovação nas empresas participantes e, com base nesses estudos, propuseram planos de ação direcionados a melhorar suas capacidades competitivas. A implantação de inovações foi monitorada sistematicamente e observada suas evoluções nesse período em cada empresa. A autora do presente trabalho orientou a seleção e a organização dos dados de campo para elaboração de artigos dos agentes. Durante as orientações, foram estimuladas reflexões sobre as principais situações que contribuíram e que dificultaram o desenvolvimento da inovação nas empresas acompanhadas, bem como foi aplicado questionário para mensurar a experiência empírica. Revelam-se indicativos requeridos para estabelecimento e manutenção da inovação em MPE.
\end{abstract}

Palavras-chave: Micro e Pequenas Empresas. Inovação.

\section{ABSTRACT}

The objective of this paper is to indicate and discuss the practical factors that enable small and medium enterprises (SMEs) to be innovative, strengthened and updated. The discussion was based on the experience in the field of eighteen local innovation agents, professionals trained by SEBRAE (Brazilian Support Service for Micro and Small Enterprises), who are also holders of a CNPq (National Council for Scientific and Technological Development) scholarship. The agents monitored an initial total of 784 SMEs in the state of São Paulo, Brazil, over a two-year period. The agents performed management and innovation diagnostics in the participating companies and based on the results of these studies, proposed action plans to improve their competitive capabilities. The implementation of innovations was systematically monitored their evolutions observed in each company. The author of this paper guided the selection and organization of the field data for the elaboration of the agent's articles. During the orientation process, reflections were stimulated on the main situations that contributed to or hindered the development of innovation in the companies monitored. Also, a questionnaire was applied to measure the agents' empirical experience. Key indicators for the establishment of and maintenance of innovation in SMEs are revealed.

Key-words: Small and medium businesses. Innovation. 


\section{RESUMEN}

El objetivo de este trabajo es indicar y discutir que fundamentos prácticos hacen con que las micro y pequeñas empresas (MPE) sean innovadoras, fortalecidas y actuales. La discusión tuvo como base la experiencia de campo de 18 agentes locales de innovación, profesionales capacitados por el SEBRAE, becarios de CNPq, que acompañaron mensualmente, por dos años, un total de 784 MPE del estado de São Paulo. Los agentes realizaron diagnósticos de gestión y de innovación en las empresas participantes y, con base en estos estudios, propusieron planos de acción direccionados a mejorar sus capacidades competitivas. La implantación de innovaciones, de cada empresa, fue monitoreada sistemáticamente y observada junto con sus evoluciones durante el período estudiado. La autora del presente trabajo orientó la selección y la organización de los datos de campo para elaboración de artículos de los agentes. Durante las orientaciones, fueron estimuladas reflexiones sobre las principales situaciones que contribuyeron y que dificultaron el desarrollo de la innovación en las empresas acompañadas, como también la aplicación del cuestionario para mensurar la experiencia empírica. Se revelaron indicativos requeridos para estabelecimiento y mantenimiento de la innovación en MPE.

Palabras clave: Micro y Pequeñas Empresas. Innovación.

\section{INTRODUÇÃO}

Os pequenos negócios têm sido considerados como de incontestável importância em diversos países, uma vez que as micro e pequenas empresas (MPE) exercem papel fundamental em aspectos sociais e econômicos, tais como no desenvolvimento do empreendedorismo (self employment); na criação majoritária de postos de trabalho; no desenvolvimento da inovação; e na necessidade de considerar a influência do crescimento dos pequenos negócios sobre 0 estabelecimento de políticas urbanas, sociais e econômicas (BROWN et al., 1990; NEUMARK et al., 2011; OIT, 2015; STOREY, 2016).

Apesar da importância das MPE e do vigor econômico que representam em diversos países, tais empresas também se constituem nos principais nichos de informalidade, baixa produtividade, com necessidade de atenção em relação à proteção social e às condições de trabalho, segundo relatório sobre a América Latina (OIT, 2015).

Sabe-se que o contexto mundial apresenta cenários rapidamente mutáveis e altamente competitivos. $\mathrm{Na}$ situação brasileira, embora favorável às MPE entre os anos de 2008 e 2014, quando houve a expansão do PIB e do rendimento médio da população, queda do desemprego e dos juros e melhora no ambiente legal para as MPE, lamentavelmente cabe mencionar que a média do índice de mortalidade dessas empresas ainda gira em torno de $25 \%$, isto é, cerca de um quarto delas encerra suas atividades antes de seus dois primeiros anos de existência (SEBRAE, 2016).

A implementação de inovações tem sido considerada fator de sobrevivência das MPE, possibilitandoIhes maior produtividade, originalidade e competitividade. Uma pesquisa do SEBRAE-SP (2008) apontou que entre as MPE que passaram por processos de inovação, $62 \%$ viram crescer a produção, $46 \%$ notaram aumento do faturamento e $39 \%$ apontaram maior produtividade por empregado.

Entretanto, o processo ou as atividades de inovação empresarial podem ser obstruídos por diversos motivos, como por razões que impedem que as ações de inovação sejam iniciadas até fatores que as refreiam ou as impactam negativamente. Tais obstáculos à inovação podem variar em função da economia, do setor, do segmento, do mercado, do ambiente legislativo, da localização geográfica e outros (OECD; EUROSTAT, 2005).

Uma importante fonte de dados sobre inovação empresarial é desenvolvida pelo Instituto Brasileiro de Geografia e Estatística (IBGE) através da Pesquisa de Inovação Tecnológica (PINTEC), com uma produção de estatísticas e indicadores setoriais e geográficos sobre o esforço empreendido para a inovação de produtos e de processos nas empresas brasileiras, contemplando tópicos como: fontes de financiamento, dispêndios com atividades inovativas, impacto das inovações no desempenho das empresas, arranjos cooperativos, papel dos incentivos governamentais, obstáculos às ações de inovação, etc. (IBGE, 2016).

No entanto, grande parte dos trabalhos difundidos na área acadêmica e institucional tem colocado ênfase aos fatores de impacto negativo sobre as atividades inovativas e, geralmente, retratado a percepção das empresas. E, embora haja uma variedade de pesquisas sobre ambiente propício à inovação, partindo-se do 
ponto de vista dos empresários e/ou dos colaboradores, e também uma vasta discussão sobre a importância da liderança neste contexto, ainda assim há certa carência de trabalhos que contribuam para observar características do ambiente propício à inovação a partir de outros pontos de vista.

0 conhecimento dos fatores primordiais que contribuem para a inovação, no âmbito dos pequenos negócios, tem importância para a formulação de estratégias administrativas, especialmente para empreendedores, pois uma boa parcela das medidas empresariais pode ser definida pelo aprimoramento dos processos com base em soluções e métodos mais assertivos, que definem um ambiente propício à inovação.

Assim, considerar a inovação com foco na empresa e nas atividades assumidas por elas na busca por assimilar as forças que levam ao sucesso no desempenho do negócio, assim como nas barreiras à inovação, constituem dados relevantes e de importância central para a formulação de políticas públicas (OECD; EUROSTAT, 2005) e administrativas, voltadas para produtividade e para o desempenho comercial e social das MPE.

Logo, a pergunta de pesquisa é a seguinte: Com base na observação empírica, de um ponto de vista diverso do empresário, isto é, de agentes locais de inovação, quais são os fatores primordiais que definem a "empresa inovadora"?

Desta maneira, este trabalho tem como objetivo geral realizar um levantamento quali-quantitativo e uma discussão sobre fatores que se destacam ao contribuir para o desenvolvimento da inovação empresarial e que se sobressaem exercendo função de obstáculo à inovação, no âmbito das micro e pequenas empresas.

O objetivo específico é delimitar, com base em observação de campo de profissionais da área de inovação, quais foram as situações e fatores característicos da "empresa inovadora" e elucidar quais foram os principais entraves à inovação, em um conjunto de centenas de MPE acompanhadas por um período de dois anos.

Para atingir os objetivos, foram utilizadas duas fontes principais de pesquisa, sendo:

1. Análise da experiência de campo de 18 pesquisadores do Conselho Nacional de Desenvolvimento Científico e Tecnológico (CNPq), que atuam como agentes locais de inovação do Programa ALI do Serviço Brasileiro de Apoio às Micro e Pequenas Empresas (SEBRAE), e acompanharam mensalmente um total inicial de 784 MPE dos setores de comércio, serviço e indústria, nos anos de 2015 a 2017, no interior do estado de São Paulo.

2. A aplicação de um questionário junto aos agentes, objetivando e possibilitando mensurar a obtenção de conteúdo sobre o problema da pesquisa, portanto, questionando-se sobre os requisitos-chave que contribuíram para impulsionar/prejudicar a inovação nas MPE acompanhadas ao longo do Programa.

O trabalho dos agentes se fundamenta na realização de diagnósticos do estágio gerencial e da situação da inovação nas MPE. Com essa base, propõem-se planos de ação para cada uma das empresas, voltados a melhorar suas capacidades competitivas por meio da implementação e da gestão de inovações, como em produtos, processos, relacionamento, marca, cadeia de fornecimento, e outras - e através do aperfeiçoamento gerencial como suporte à inovação, sendo, então, as ações e os seus respectivos resultados monitorados, mensalmente, ao longo dos mais de dois anos. 0 resultado desse trabalho de acompanhamento às empresas é então apresentado e discutido em artigos científicos, elaborados pelos agentes, com suporte acadêmico de orientadores.

A autora do presente trabalho atua como orientadora do Programa ALI, conduzindo os agentes de dois escritórios regionais do SEBRAE - São Paulo, à seleção e à organização dos dados levantados junto às empresas, bem como contribuindo efetivamente para o delineamento de suas reflexões, análises e discussões dos resultados sobre a evolução da inovação em MPE e sobre os fatores que as levam a se destacar ou não em seus âmbitos.

O Programa Agentes Locais de Inovação (Programa ALI) corresponde a um projeto de extensão nacional que visa realizar o repasse gratuito de técnicas a micro e pequenos empreendedores do território brasileiro, de modo a melhorar suas empresas por meio da implantação de ações de inovação. Trata-se de uma parceria celebrada entre o SEBRAE, que promove a capacitação dos agentes e organiza a sua prática de 
acompanhamento das empresas, voluntariamente aderidas ao Programa, e o CNPq, que fomenta o projeto, do qual os agentes são bolsistas (CNPq, 2017; SEBRAE, 2017).

Deste modo, o Programa ALI está em consonância com a necessidade de estimular a inovação nas MPE brasileiras na prática, ao mesmo tempo em que se constitui em uma rica fonte de dados primários e de informações, obtidos por meio de pesquisa engajada, com variado potencial de realização de análises. Neste contexto, ainda com base na descrição da percepção dos agentes locais de inovação, o presente trabalho busca, também, contribuir com a discussão e melhorar a definição do conceito de "empresa inovadora".

\section{REFERENCIAL TEÓRICO}

\subsection{Inovação Empresarial}

Uma das principais tendências empresariais da atualidade é a inovação, um termo estudado por diversas áreas do conhecimento, e que tem sido frequentemente utilizado também nas esferas acadêmica, ambiental, social e política.

Galli e Torreggiani (2006) já haviam pormenorizado que todas as empresas se inserem em um ambiente de concorrência, muito amplo e agressivo, em que ocorre 0 aumento da pressão competitiva internacional, a rápida evolução da tecnologia, o forte processo de descentralização produtiva das grandes empresas, e a evolução contínua da exigência dos clientes. Em tal contexto, em cuja vantagem competitiva se esvai sempre muito fácil e velozmente, faz-se imperativo o reforço da capacidade de inovação, tanto advinda do governo quanto do próprio negócio.

A inovação representa uma mudança no status quo e sua definição envolve o descobrimento de novidades e a comercialização de tais descobrimentos. Essas novidades podem ser divididas em duas categorias: exploração de novas possibilidades e reciclagem de velhas assertividades (OKE et al., 2009, p. 64).

Em outras palavras, a inovação empresarial é considerada como a inserção de novidade (inovação radical/de ruptura) ou aprimoramento (inovação incremental) no ambiente produtivo ou social, que resulta em novos ou modificados produtos, processos ou serviços, com o objetivo de criar diferencial, neutralizar a concorrência ou aumentar a produtividade (SEBRAE-PR, 2010).

Assim, a inovação pode se dar em produtos, processos, marketing ou ser no âmbito organizacional (SEBRAE-PR, 2010), ou mesmo uma mudança de padrão na esfera comportamental (JIMÉNEZ-JIMÉNEZ; SANZ-VALLE, 2011). São exemplos: a inserção de um método mais favorável, uma melhoria no sistema organizacional ou nas práticas de negócios, assim como um aperfeiçoamento na organização do local de trabalho ou mesmo nas relações da empresa, por exemplo, com fornecedores, parceiros e clientes.

$O$ conceito de inovação se refere a mudanças nas empresas, caracterizadas pelos seguintes aspectos (OECD; EUROSTAT, 2005): a inovação está associada à incerteza sobre os resultados de implementação; ela envolve investimento financeiro com potencial de retorno; a empresa inventora raramente se apropria plenamente dos benefícios da inovação, devido ao efeito de transbordamento, ou seja, outras empresas podem adotar a invenção por imitação; a inovação se utiliza de novos conhecimentos ou de uma nova combinação de conhecimentos já existentes; a inovação tem como objetivo melhorar o desempenho de uma empresa com 0 ganho de uma vantagem competitiva (ou mesmo a sustentação da competitividade já presente) por meio da acentuação ou mudança da demanda de seus produtos, por exemplo, com a conquista de novos mercados.

Também se tem frisado que um produto ou método pode ser tido como inovador se é novo para a empresa que o implementa, ainda que trivial no mesmo setor, segmento, na concorrência ou em outros negócios (SEBRAE-PR, 2010).

\subsubsection{A Inovação Empresarial é um Processo}

Não é suficiente ser criativo e apresentar novas possibilidades e ideias, implementação é um aspecto chave do processo de inovação (OKE et al., 2009:64). Tidd et al. (2001 apud OKE et al. 2009, p. 67) se referiram à inovação empresarial como a mudança que inclui desde a criação até a comercialização do novo "conhecimento". Desta maneira, a inovação não se restringe à criatividade ou à invenção, pois a nova ideia precisa ser plenamente implementada, ou seja, as novidades ou melhorias relevantes para a empresa precisam 
ser planejadas, executadas e devem trazer algum impacto para a empresa, para então serem consideradas como inovação.

Assim, as inovações organizacionais correspondem a um suporte das inovações tecnológicas (produto e processo), pois, além de aperfeiçoarem a qualidade e a eficiência do trabalho, proporcionam a intensificação da troca de informações e o refinamento da capacidade de aprender e de aplicar conhecimentos e tecnologias nas empresas (OECD; EUROSTAT, 2005). Assim, novas práticas de marketing, por exemplo, podem funcionar como alavancas para o sucesso de novos produtos, do mesmo modo que o marketing pode contribuir para inclusão de novas melhorias nesses produtos, em função de pesquisas de satisfação com o cliente, por exemplo.

Em vista disso, as inovações organizacionais, assim como as de marketing, completam um alicerce mais competente para absorver as mudanças que impactam o desempenho da empresa, elevando o resultado financeiro e contribuindo para o acúmulo de conhecimento (OECD; EUROSTAT, 2005).

De acordo com Van De Ven et al. (2000 apud MACHADO, 2007), o processo de inovação possui cinco componentes-chave, que devem ser considerados na gestão de inovações: a. ideias (criação, desenvolvimento e implementação); b. pessoas (elas precisam ser recrutadas, organizadas e dirigidas e haverá interação de diferentes habilidades, níveis de energia, percepções); c. transações (relacionamento entre pares, gestores e entre estes e os subordinados, comprometimento para obter e alocar recursos e envolvimento entre diferentes unidades ou organizações); $d$. contexto (cenário ou ambiente institucional - deve abranger uma concepção macro, que inclua a comercialização); e. resultado (ideias podem resultar em inovação ou erro, ambos precisam ser monitorados e mensurados) e tal processo é composto por uma série de eventos temporais decorrentes da interação entre as pessoas para desenvolver e implementar novidades em uma instituição, com a finalidade de atingir um resultado, cuja mudança em um dos componentes afeta os outros.

Desse modo, a inovação deve ser compreendida como um processo interativo, contínuo, em que mudanças tecnológicas, gerenciais e organizacionais estão interconectadas e interligadas em uma espiral de melhoramento da performance do negócio (GALLI; TORREGGIANI, 2006).

\subsubsection{Empresa Inovadora}

A definição básica de empresa inovadora é aquela que implementou algum tipo de inovação (idealizou/adotou, planejou, executou e teve resultado) no período em análise, porém o conceito pode ser redefinido em função dos objetivos de pesquisa ou de políticas públicas (OECD; EUROSTAT, 2005).

0 conceito adotado no presente trabalho, além da definição básica, inclui a ideia de que a empresa inovadora obteve, no período analisado, crescimento ou estabilidade financeira, aumentou a competitividade ou conseguiu mantê-la, aumentou ou preservou a produtividade, ou conquistou novos mercados. A estabilidade também pode ser considerada um ganho ou impacto positivo em circunstâncias de crise econômica, por exemplo, ou queda de demanda no setor, como por aumento da concorrência.

Além disso, considera-se que, na empresa inovadora, a estabilidade ou as conquistas relacionadas ao crescimento se deram por meio de ações de inovação geridas em uma curva ascendente de uma organização informal (frequente no caso das MPE) para uma organização formal dos processos de gestão da inovação (controlada, planejada, estratégica), isto é, com sistematização da geração de novidades e implementação de inovações. Nesse sentido, vale destacar que, segundo SEBRAE-PR (2015), a empresa inovadora domina o processo de gestão da inovação.

A empresa inovadora é aquela que pratica rotineiramente a gestão da inovação (SEBRAE, 2017), independentemente do tipo de inovação e em qual área da empresa ela ocorre e, segundo Oke et al. (2009, p. 64), estão constantemente monitorando as perspectivas de exploração de novas possibilidades e de reciclagem de velhas assertividades. E, para que uma empresa possa ser considerada inovadora, ela deve ter bem desenvolvida a ambiência inovadora, ou seja, torna-se fundamental a presença de um clima organizacional que favoreça a inovação (BACHMANN; DESTEFANI, 2008).

\subsection{Inovação em Micro e Pequenas Empresas}


Com essa ampla possibilidade de concretização da inovação no ambiente das MPE, ainda é possível registrar que há uma crença de que inovar significa "amodernar-se" ou renovar os maquinários, ou a informatização (GALLI; TORREGGIANI, 2006). Assim, há ainda um campo aberto para que muitos empresários sejam convencidos de que a inovação pode ocorrer nas diversas áreas da empresa, e que para poder se beneficiar plenamente das inovações, mesmo as tecnológicas, requer fazer mudanças, com aperfeiçoamento organizacional e gerencial.

Também se considera que, nas MPE, o negócio e o empreendedor habitualmente se confundem. Com isso, as ações propostas para alavancar a inovação muitas vezes podem ser "compradas" ou "aceitas" pelos empresários. Então, ainda que a inovação seja em geral a origem das tendências, nas MPE deve-se fazer 0 contrário: essas "(...) empresas devem priorizar as inovações para se adequarem às tendências" (SEBRAE-PR, 2010, p. 147) sempre mutáveis. Desta maneira, as inovações frequentemente ainda são "vendidas" aos micro e pequenos empresários, em geral desprovidos de conhecimentos fundamentais sobre gestão e inovação, o que pode representar impeditivo para o sucesso da empresa.

\subsubsection{Dimensões da Inovação nas Micro e Pequenas Empresas}

No caso específico dos pequenos negócios, considera-se que a inovação pode ser concebida, mensurada e implementada em variadas dimensões, que fazem parte do contexto das MPE. Com base nesse ideal, Sawney et al. (2006) definiram doze dimensões da inovação, sendo elas:

1. Oferta (produtos);

2. Plataforma (recursos e modo de produção);

3. Marca (identificação do negócio/transmissão da imagem da empresa ao cliente);

4. Clientes (consumidores/pessoas ou organizações que consumem produtos ou serviços);

5. Soluções (combinação customizada de bens, serviços e informações capazes de solucionar o problema/a demanda do cliente);

6. Relacionamento (experiência do cliente quando interage com a empresa);

7. Agregação de Valor (novas formas de gerar receita/de captar ou transmitir valor ao cliente);

8. Processos (configuração das atividades sequenciais para geração de produtos ou serviços);

9. Organização (estrutura humana da empresa/parcerias estabelecidas com o papel e a responsabilidade dos colaboradores);

10. Cadeia de Fornecimento (sequência de atividades que movimentam dos produtos e a informação da origem à entrega, abrangendo a logística do negócio);

11. Presença (canais de distribuição que a empresa utiliza para pôr seus produtos no mercado e locais onde os produtos podem ser encontrados para aquisição);

12. Rede (conexão entre produtos e clientes).

Bachmann e Destefani (2008), em um trabalho cujo objetivo era a proposição de uma metodologia de diagnóstico da inovação para pequenas empresas, o "Radar da Inovação", adaptaram esse conjunto de dimensões da inovação de Sawney et al. (2006) e adicionaram mais uma dimensão a ele, a:

13. Ambiência Inovadora (ambiente empresarial propício à inovação/conjunto de ferramentas, processos e atitudes que promovem ou motivam os colaboradores a criarem novidades ou propor melhorias). 


\subsection{Fatores de Impacto sobre a Inovação}

\subsubsection{O Processo Criativo e a Liderança}

O processo criativo da inovação é primariamente um produto da imaginação, incluindo-se a aptidão para enfrentar riscos, desafiar o status quo, e de conectar diferentes matrizes de pensamento, reflexões, habilidades, e de aplicar tudo na geração das novidades. Assim, o estado mental da pessoa que gera novas ideias é um fator essencial e é influenciado pelo seu entorno (OKE et al., 2009, p. 68).

Ao mesmo tempo, embora algumas inovações possam surgir de ideias advindas de membros de uma equipe que não estão necessariamente na liderança ou gestão, geralmente as inovações tendem a ser o resultado de uma estratégia competitiva direcionada ao mercado no qual a empresa se insere (OKE et al., 2009, p. 67).

Nesse contexto, no caso das micro e pequenas empresas, pode-se tomar como estratégia a estipulação de poucas dimensões da inovação para se concentrar os esforços, em vez de tentar desenvolver várias simultaneamente (SAWNEY et al., 2006). Esta técnica pressupõe o conhecimento prévio das características e da situação da empresa e de seu mercado, de modo a elaborar os melhores planos pela competitividade.

E para que as inovações tenham sucesso em uma organização, requer-se o comprometimento dos recursos e dos fatores envolvidos na estratégia de inovação, que são controlados por uma liderança (OKE et al., 2009 , p. 67) que, segundo Carlomagno e Scherer (2009), deve valorizar as pessoas, pois a criatividade provém da socialização do conhecimento em uma cultura que prestigia atitudes e flexibilidade.

De acordo com Müceldili et al. (2013), diversos perfis de liderança foram estudados e discutidas as relações entre suas características e o desenvolvimento da inovação nas empresas, como os perfis "ambidestro" (ROSING et al., 2011), "transformacional" (GUMUSLUOGLU, 2009), "transacional" (PIETERSE et al., 2010) e "autêntico" (REGO et al., 2012). Müceldili et al. (2013) validaram pesquisas anteriores que mediram uma estreita relação entre o "líder autêntico" e a produtividade em inovação. Estabeleceram que as características do líder autêntico estimulam a criatividade dos colaboradores para inovar.

O SEBRAE (2015) assume que a ideia de "liderança autêntica" é aquela capaz de alavancar o sucesso da inovação em uma empresa por meio de um ambiente de trabalho produtivo, com engajamento dos colaboradores, gerando ideias contributivas para processo de inovação.

O perfil do líder autêntico é definido por Walumbwa et al. $(2008$, p. 94) como aquele que tem um padrão de comportamento de liderança que se baseia e que promove habilidades psicológicas positivas e também um clima ético. Uma de suas principais características é que o líder autêntico é muito consciente de si mesmo. Além disso, tem capacidade para fazer um processo equilibrado das informações, aceitando analisar opiniões contrárias às suas, sendo aberto e transparente, compartilha com seus seguidores informações úteis para a tomada de decisões; divulgando seus valores pessoais e motivadores, buscando permitir à equipe avaliar, de forma mais assertiva, a competência e a conduta de suas ações.

Outro perfil de líder que apresenta estreita relação com o sucesso da inovação é de "líder transformacional", um estilo de liderança, como o próprio nome diz, daquele que procura a transformação, mudança, isto é, o principal fio condutor da inovação. Suas principais características são: carisma, influência idealizada (ele é tido como um exemplo a ser seguido), motivação inspiradora e consideração individualizada (foca nas necessidades individuais de desenvolvimento e suporte aos colaboradores). Tal estilo de liderança procura promover simulações intelectuais, encorajando os empregados a reexaminar suposições e velhas maneiras de fazer as coisas, bem como a identificar novas abordagens (OKE et al., 2009, p. 68).

Assim, o líder que faz a gestão voltada à inovação proporciona um ambiente de trabalho mais produtivo e agradável, contribuindo para que haja um espírito de equipe e para o sentimento de confiança e engajamento dos colaboradores, que passam a ver mais propósito em seus trabalhos, ficando mais criativos e gerando ideias fundamentais no processo de inovação empresarial (SEBRAE, 2015).

\subsubsection{Fatores Facilitadores e Dificultadores da Inovação}

O setor no qual se insere a atividade da empresa, seu mercado, a região geográfica onde se instala a empresa, a conjuntura socioeconômica e o tipo de inovação devem ser considerados como fatores que podem

Revista Alcance - Eletrônica - vol. 24 - n. 4 - out./dez. 2017 
impactar o desenvolvimento da inovação (OECD; EUROSTAT, 2005) de forma positiva ou negativa e, assim, podem influenciar a capacidade de inovação das empresas.

Em poucas palavras, segundo Mohr (1969 apud ALEXANDRE; SILVA FILHO, 2014), a inovação é uma função da interação entre a motivação de inovar, a força dos obstáculos contra a inovação e a disponibilidade de recursos para superar tais obstáculos.

\subsubsection{Obstáculos à Inovação}

Os obstáculos à inovação podem ter diversas origens: econômica, organizacional (rigidez, centralização da gestão, etc.), informacional (sobre o mercado, tecnologias, etc.), técnica (pessoal qualificado, serviços técnicos, etc.), dentre outras (cooperação, consumidores, normas e regulamentos, etc.) (OECD; EUROSTAT, 2005; KUHL; CUNHA, 2013). Segundo Oecd e Eurostat (2005, p. 113), no Manual de Oslo, os fatores que agem dificultando a inovação são:

1. Econômicos: riscos excessivos identificados pelos empreendedores; custo muito alto ou prazo muito longo de retorno do investimento em inovação; falta de fontes apropriadas de financiamento ou de oportunidades de cooperação;

2. Fatores da empresa: potencial de inovação insuficiente (P\&D, recursos, etc.); falta de pessoal qualificado; falta de informações tecnológicas ou sobre o mercado; gastos com inovação difíceis de controlar; resistência a mudanças no ambiente empresarial; deficiência na disponibilidade de serviços externos e outros;

3. Outras razões: falta de tecnologia adequada para a ideia inovadora; falta de infraestrutura; fraca proteção dos direitos de propriedade tecnológica, intelectual; legislação, regulamentos, normas, sistemas/padrões exigidos, impostos; clientes indiferentes a novos produtos e processos; nenhuma necessidade de inovar devido a inovações anteriores.

Em um estudo sobre obstáculos à implementação de inovações no Brasil, que teve como base a percepção dos empresários, Kuhl e Cunha (2013) encontraram diferentes percepções para diferentes tipos de empresas. Entretanto, as dificuldades econômicas e a falta de informação sobre a tecnologia e de pessoal qualificado foram identificadas como as barreiras que mais impedem às empresas inovarem.

Uma pesquisa realizada pela Federação das Indústrias do Estado de São Paulo (FIESP) revelou, com base em estudo com 200 empresas, que os principais obstáculos à inovação são riscos econômicos (35\%), problemas relacionados com financiamento $(27 \%)$, custos elevados $(25 \%)$, dificuldades na obtenção de informações (17\%) e fatores internos à empresa (12\%) (FIESP, 2011 apud ALEXANDRE; SILVA FILHO, 2014).

\subsubsection{Fatores que Contribuem com a Inovação}

A inovação exige um "ambiente propício", caracterizado pela ambiência inovadora, que tem no clima organizacional os seguintes requisitos (SEBRAE-PR, 2010; 2015):

1. Relacionamento com o conhecimento de fontes externas à empresa e à valorização do conhecimento obtido.

2. Conhecimento de fontes de financiamento para a inovação;

3. Prática da experimentação (testes contínuos de novos produtos, processos, métodos, etc.) e cultura da aceitação de erros e ousadia em implementar novos produtos e processos;

4. Liderança voltada estrategicamente para a inovação, com capacidade de direcionar, eficientemente e estrategicamente, os recursos necessários e disponíveis no processo de inovação.

Além de uma liderança transformacional, isto é, voltada para a inovação, Oke et al. (2009, p. 67) também consideram importante que a empresa tenha: 
5. Capacidade tecnológica ou investimento em Pesquisa \& Desenvolvimento (P\&D) para o projeto de inovação.

Alexandre e Silva Filho (2014) levantaram mais elementos que facilitam a inovação, sendo eles:

6. Disposição da empresa para assumir riscos;

7. Disposição de expressar e de trocar informações, por meio do compartilhamento do conhecimento;

8. Uma estrutura descentralizada, em oposição à centralização, que pode dar abertura e incentivar a geração de novidades;

9. Uma força de trabalho qualificada.

Van De Ven et al. (2000 apud MACHADO, 2007) encontraram uma relação de fatores que fazem parte de um "ambiente propício" à inovação:

10. Eficiência percebida com as inovações já implantadas;

11. Formalização e padronização de procedimentos - quanto mais bem determinadas as regras e as tarefas, maior a percepção de eficiência das inovações;

12. Com relação à equipe, são fatores que facilitam a inovação: expectativa de prêmios e recompensas; possibilidade de influência nas decisões por parte dos colaboradores é estimulante; liberdade para expressar dúvidas; aprendizagem encorajada; percepção da liderança como promotora da inovação; percepção de interdependência e importância entre pessoas e grupos para fazer dar certo o processo; dedicação à inovação; comunicação frequente entre as pessoas; controle de conflitos.

Knox (2002 apud MACHADO, 2007) lista aspectos que sustentam uma organização inovadora: a cultura e o clima organizacional; as capacidades e as habilidades de gestão; o controle e a estrutura organizacional;

novos produtos e desenvolvimento de processos; salientando que a inovação contínua se baseia nas atitudes e nas capacidades das pessoas, que, por sua vez, são dependentes de uma cultura que encoraja 0 empreendedorismo individual e o trabalho em times.

\section{PROCEDIMENTOS METODOLÓGICOS}

\subsection{Metodologia do Programa ALI - SEBRAE/CNPq}

O Programa ALI, de abrangência nacional, consiste na extensão tecnológica destinada às micro e pequenas empresas, realizada por bolsistas do CNPq, capacitados pelo SEBRAE, para atuarem, ao longo de 28 meses, como agentes locais de inovação, com o objetivo de acompanhar empresários na prática da implantação e/ou gestão da inovação em suas empresas, de modo a torná-las inovadoras e com maior capacidade competitiva.

O período de coleta de dados se insere na fase 2015-2017 do Programa ALI (cerca de 22 meses de acompanhamento mensal das empresas pelos agentes, em campo), incluindo-se neste período: 1. A prospecção e adesão de MPE ao Programa; 2. A realização de diagnósticos de gestão (conforme FNQ, 2014) e do grau de inovação da empresa e das 13 dimensões da inovação de Sawney et al. (2006) e Bachmann e Destefani (2008) (utilizando o Radar da Inovação, de BACHMANN; DESTEFANI op. cit.), em cada uma das empresas; 3. A proposição de Planos de Ação voltados para a implantação e gestão da inovação, personalizados para cada MPE e elaborados com base nos diagnósticos; 4 . Visitas mensais dos agentes a todas as empresas para monitorar as ações e os resultados; 5 . A repetição dos diagnósticos de gestão e de inovação após a implementação dos Planos de Ação pelas empresas, com ajustes nestes; 6 . Elaboração de artigo apresentando 
análise evolutiva do grau de inovação das empresas e das 13 dimensões do Radar da Inovação, entre $01^{\circ}$. diagnóstico (logo após a adesão das empresas) e $02^{\circ}$. diagnóstico (após a execução dos Planos de Ação).

\subsection{Caracterização da Amostra}

\subsection{1. Área de Estudo}

A região de acompanhamento das MPE constituiu municípios atendidos pelos Escritórios Regionais (ER) do SEBRAE de São José dos Campos (incluindo este e também os municípios de Jacareí, Taubaté, Caçapava, Tremembé e Santa Branca) e do ER SEBRAE de Alto Tietê (municípios de Mogi das Cruzes, Suzano, Ferraz de Vasconcelos, Poá, Itaquaquecetuba, Guararema, Biritiba Mirim e Salesópolis), no estado de São Paulo. Trata-se de duas das regiões mais desenvolvidas do estado, em termos de infraestruturas urbanas e instalações de atividades econômicas diversas, sendo São José dos Campos um dos polos de desenvolvimento científico e tecnológico do país.

A soma da população total do conjunto destes municípios, estimada para 2016, é de 2.833 .893 de habitantes (variando de 14.667, em Santa Branca a 695.992 em São José dos Campos). Nesse conjunto, a média do Índice de Desenvolvimento Humano (IDH) é de 0,759 (com variação de 0,712 em Biritiba Mirim a 0,807 em São José dos Campos) e o PIB per capta médio é de $R \$ 31.089,00$ (variando de $R \$ 11.003,00$ em Salesópolis a 55.534,00 em Guararema). Mogi das Cruzes também se releva com a segunda maior população da região: 429.321 habitantes e IDH exatamente igual à média do estado de São Paulo, ou seja, 0,783 (IBGE, 2014).

No conjunto espacial que engloba as regiões de São José dos Campos e de Alto Tietê, as MPE somam mais de 108.000 estabelecimentos, com destaque para empresas de serviços e comércios, as quais representam cerca de $81 \%$ das empresas da região (SEBRAE, 2012).

\subsubsection{Micro e Pequenas Empresas Acompanhadas pelos Agentes}

De acordo com as definições estabelecidas na Lei Complementar 123/2006 e 155/2016 (BRASIL, 2017), a microempresa é categorizada como aquela cuja receita bruta, em cada ano-calendário, seja igual ou inferior a $\mathrm{R} \$ 360.000,00$ e a empresa de pequeno porte como aquela cuja receita bruta, em cada ano-calendário, seja superior a $R \$ 360.000,00$ e igual ou inferior a $R \$ 4.800 .000,00$. Entretanto o Programa ALI (SEBRAE/CNPq) utiliza a definição imediatamente anterior a esta, na qual a empresa de pequeno porte ainda tinha o teto de $R \$$ $3.600 .000,00$.

O trabalho de acompanhamento dos agentes iniciou com 784 MPE (julho de 2015) dos setores industrial, comercial e de serviços, que se reduziram, paulatinamente, a 504 MPE (até maio/2017), distribuídas entre os setores de atividades, conforme demonstrado na Figura 1, as quais se mantiveram no Programa, cumprindo os Planos de Ação propostos até o segundo ciclo de diagnósticos. Desta maneira, inicialmente eram cerca de 40 empresas por agente e no período da elaboração do artigo, após 22 meses de acompanhamento, cada agente contava com uma média de 28 empresas. 
Figura 1 - As 504 MPE acompanhadas pelos agentes locais de inovação - que cumpriram os planos de ação em inovação e sua distribuição por setores

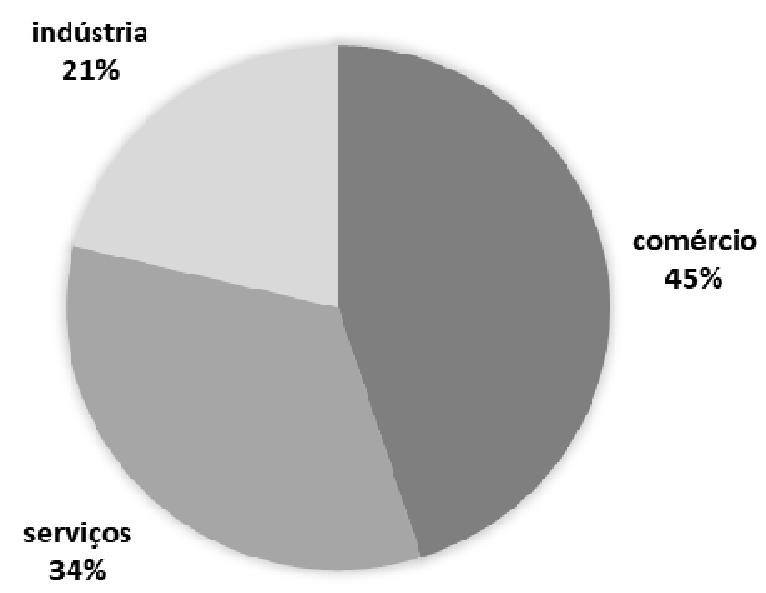

Fonte: Elaboração e organização da autora (2017).

Algumas empresas deixaram o Programa porque tinham crescido muito, tornando-se empresas de médio porte; outras desistiram de inovar ou mesmo encerraram suas atividades; algumas, mesmo que ainda sendo acompanhadas pelos agentes, não podiam ser consideradas na análise, pois não haviam implementado as ações de inovação do Plano de Ação, portanto ainda não tinham "evoluído" em dimensões da inovação.

Os Planos de Ação elaborados pelos agentes resultaram na evolução de certas dimensões da inovação (de SAWNEY et al., 2006; BACHMANN; DESTEFANI, 2008), indicando em quais áreas as empresas mais inovaram/investiram. A Figura 2 mostra as áreas de maior evolução em inovação apresentada pelas empresas, segundo a observação dos agentes (número de vezes em que os agentes indicaram determinadas dimensões como as mais desenvolvidas quando perguntado sobre o conjunto de MPE acompanhadas).

Figura 2 - Dimensões da inovação mais desenvolvidas após a aplicação do Plano de Ação nas empresas acompanhadas

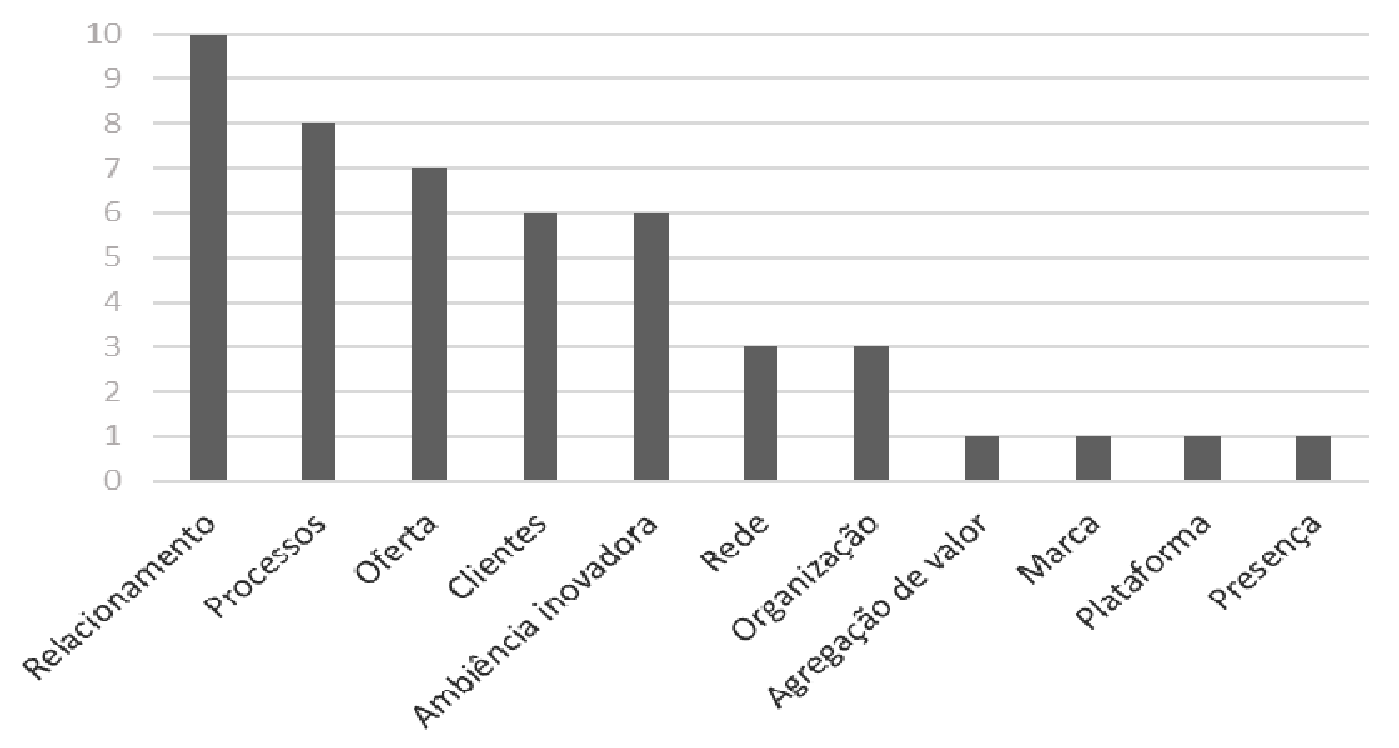

Fonte: Elaboração e organização da autora (2017). 


\subsubsection{Agentes Locais de Inovação: Capacitação e Perfil}

Durante o período de capacitação dos agentes (cerca de 160 horas) pelo SEBRAE, eles tomam contato, por meio de textos e de simulações, com uma gama de temas que contribuem para subsidiar sua observação de campo em relação às empresas e aos empresários, tais como: "Inovação e gestão da empresa de pequeno porte" e "Diagnóstico e plano de ação". Além de conceitos e estratégias de gestão da inovação e das ferramentas de mensuração, também são estudados os "Fatores que facilitam e dificultam a inovação" e "O papel do líder no processo de inovação" (SEBRAE, 2015).

Ao longo do processo de acompanhamento das empresas, os agentes, sendo 10 do ER SEBRAE de São José dos Campos e 08 do ER SEBRAE de Alto Tietê, tiveram a possibilidade de observar sistematicamente o comportamento de centenas de empresários, líderes, gestores e colaboradores, com a mensuração de resultados das empresas.

Em adição ao subsídio teórico e à prática de campo, durante o período de elaboração de seus artigos, os agentes realizam breve revisão bibliográfica, principalmente sobre inovação e gestão de MPE, comportamento empreendedor e outros temas mais específicos, em função das dimensões da inovação e/ou dos setores econômicos destacados na análise de seus artigos. A elaboração do artigo é uma oportunidade de organizar e refletir sobre sua experiência de campo, com a discussão da evolução da inovação no conjunto de empresas que cada agente acompanhou.

Com relação ao perfil dos agentes, aplicou-se um questionário que constatou suas idades - de 23 a 43 anos (29 anos, em média); seu tempo de experiência profissional - possuem 2 a 20 anos de exercício (em média, 6 anos); foram graduados em diversas áreas do conhecimento - exatas (34\%), gerenciais (33\%), biológicas $(22 \%)$ e humanas (11\%), formando-se em escolas de nível superior públicas $(78 \%)$ e privadas $(22 \%)$, sendo que $27 \%$ deles possuem/estão cursando pós-graduação lato sensu (especialização/MBA) e 17\% possuem/estão cursando pós-graduação stricto sensu (mestrado).

\subsection{Procedimentos para Definição dos Requisitos-Chave das Empresas Inovadoras}

Durante o período de orientação dos artigos, foi estabelecido um sistema de discussões orientadoraorientando para que cada agente fundamentasse, com base em sua experiência de campo, a indicação dos caminhos que as MPE e os empresários devem seguir/evitar, pela inovação como forma de competitividade, em função da observação das empresas que mais evoluíram em inovação e gestão (e das que menos evoluíram), segundo os diagnósticos e as análises evolutivas das empresas, e segundo a percepção/aprendizagem empírica de cada agente. Desta maneira, buscou-se instigar a reflexão dos agentes sobre as atitudes dos empresários/ações implantadas nas empresas e situações que contribuem ou não para desenvolver/sustentar a inovação.

Adicionalmente, foi aplicado um questionário junto aos agentes como subsídio à obtenção de dados mais objetivos (junho/2017), coletando-se respostas mais diretas sobre o comportamento dos líderes/gestores das empresas, e das ações implantadas, que levam as MPE a estarem no caminho do sucesso por meio da inovação.

O questionário compôs-se de questões abertas, indagando aos agentes quais são as "palavras-chave" (requisitos) e quais são as respostas (descritivas) para as seguintes situações: "Inovação em MPE"; "Empreendedor inovador/de sucesso"; "Atitudes/contextos que impedem a inovação"; "Comportamentos/práticas de empreendedores que obtém bons resultados"; "Primeiros passos da inovação/ações para manter a inovação"; "Dificuldades enfrentadas pelos empresários para inovar"; "Influência do Programa ALI na melhoria das empresas". As questões, por serem abertas, também possibilitam, além de contabilizar a importância dos requisitos-chave das MPE inovadoras, subsídio para descrevê-los.

Os dados da aplicação do questionário foram então classificados e analisados em matrizes (Excel/Windows), interpretados e reorganizados em tabelas e gráficos para apresentação e discussão dos resultados. 


\section{APRESENTAÇÃO, ANÁLISE E DISCUSSÃO DOS RESULTADOS}

\subsection{Requisitos-Chave da Inovação em MPE}

Os resultados obtidos com esta pesquisa corroboram aspectos da literatura sobre os temas de inovação empresarial, ambiente propício à inovação, obstáculos ao desenvolvimento da inovação e relação estreita entre

liderança, gestão adequada e inovação. São destacados os fatores percebidos por agentes locais de inovação, como os mais característicos e presentes nas situações em que avaliaram as MPE como organizações inovadoras.

Mais adiante, no Quadro 1 são apresentadas a apuração e a descrição das ações, comportamentos e fatores que contribuem para que uma MPE implemente e mantenha a inovação empresarial, sendo considerada uma organização inovadora e, na Figura 3, a importância relativa desses fatores que impactam positivamente sobre o processo de inovação nas MPE.

Analisa-se que uma das características mais marcantes da empresa inovadora é a aceitação plena ou o senso de necessidade de mudanças, transformações constantes. A empresa que se permite essa abertura e flexibilidade e começa a investir em informações e conhecimentos sobre inovação se encontrará na iminência de se tornar inovadora. Neste contexto, a empresa reconhece que:

1. Precisa passar por períodos de reformulação, mesmo que parciais, que devem ser sistematicamente contínuos, em busca de melhorias e de fortalecimento;

2. Deve perseguir progressivamente o conhecimento para obter o desenvolvimento da inovação e da empresa, investindo efetivamente em competências.

Quadro 1 - Principais requisitos-chave da MPE inovadora segundo a análise de dados de pesquisa

\begin{tabular}{|c|l|}
\hline \multicolumn{2}{|c|}{ Código de conduta da empresa inovadora } \\
\hline $\begin{array}{c}\text { Cultura da } \\
\text { capacitação }\end{array}$ & $\begin{array}{l}\text { Realizar cursos e participar de eventos/feiras do setor. Também se refere a aprender e a pensar } \\
\text { sobre o contexto em que a empresa se insere, conhecendo bem o mercado, o cliente, o segmento e } \\
\text { as oportunidades. }\end{array}$ \\
\hline $\begin{array}{c}\text { Liderança } \\
\text { inspiradora/ } \\
\text { inovadora }\end{array}$ & $\begin{array}{l}\text { O líder (empreendedor, gestor) deve ser qualificado e ter conhecimento atualizado sobre gestão de } \\
\text { pessoas, deve propiciar o ambiente inovador, focando no trabalho em equipe e ouvindo seus } \\
\text { colaboradores. }\end{array}$ \\
\hline $\begin{array}{c}\text { Gestão } \\
\text { empresarial } \\
\text { adequada }\end{array}$ & $\begin{array}{l}\text { A gestão da empresa deve ser totalmente organizada em todas as áreas, com definição e } \\
\text { formalização dos processos, estabelecimento de responsabilidades e acompanhamento formal das } \\
\text { ações planejadas. }\end{array}$ \\
\hline $\begin{array}{c}\text { Dedicação } \\
\text { sistemática }\end{array}$ & $\begin{array}{l}\text { Além da vontade e da disponibilidade, refere-se, também, ao comprometimento metódico e } \\
\text { programado à inovação. Disposição e motivação proativas para fazer dar certo. }\end{array}$ \\
\hline $\begin{array}{c}\text { Aceitação do } \\
\text { novo }\end{array}$ & $\begin{array}{l}\text { Desapego ao status quo, concordando com a quebra dos paradigmas (modelos estabelecidos na } \\
\text { empresa). A mente aberta, a busca por novas ideias propicia criatividade para estabelecer as } \\
\text { inovações. }\end{array}$ \\
\hline
\end{tabular}


Figura 3 - Importância relativa dos requisitos-chave da MPE inovadora

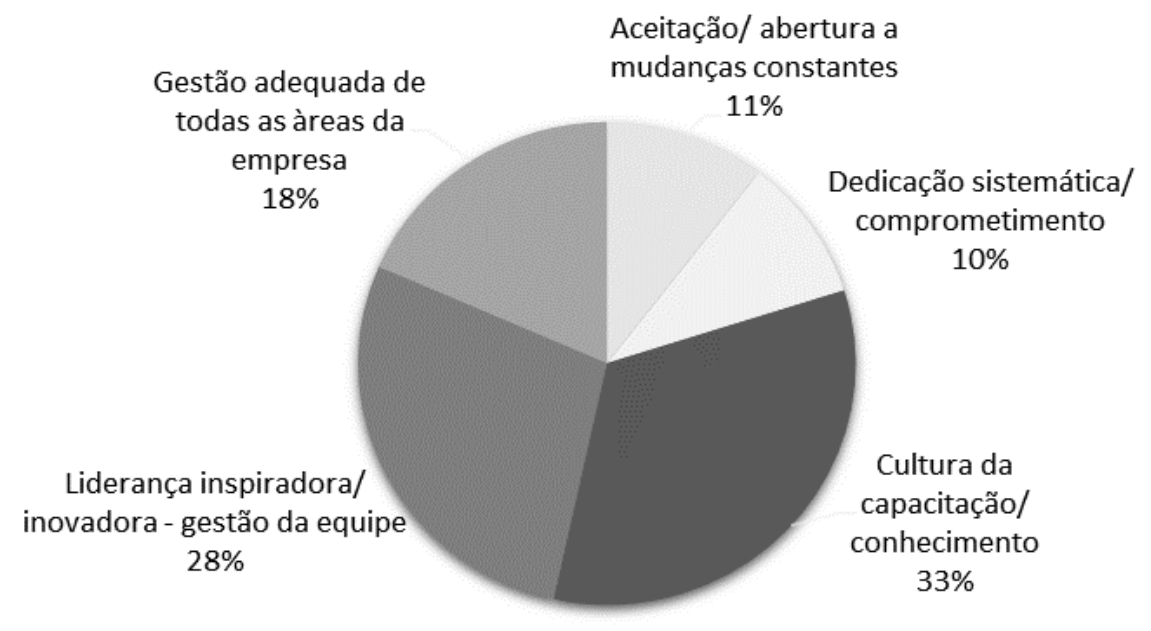

Fonte: Elaboração e organização da autora (2017).

Desta maneira, a empresa inovadora possui uma cultura de capacitação, isto é, um ambiente em que o empresário/gestor busca seu desenvolvimento pessoal e profissional, bem como de seus colaboradores, investindo regularmente em treinamento, habilidades, relacionamentos e parcerias geradores de ideias, recursos, experiências úteis e novos conhecimentos, e em pesquisas ou levantamentos de informações importantes para a empresa, como dados sobre o mercado, opinião dos clientes, fontes de financiamento para a inovação, etc., como forma a melhorar o desempenho da empresa.

Entretanto, torna-se relevante a dedicação planejada e organizada dos envolvidos, efetivamente empenhados com o processo de inovação, tendo-se como suporte uma gestão empresarial adequada em todos os setores da empresa, como na área financeira, pessoal, etc. e, da mesma maneira, é necessária a habilidade em gerenciar devidamente os recursos e projetos que levam aos bons resultados. Daí a importância, novamente, da capacitação dos gestores e colaboradores, como em gestão de projetos, em gestão da inovação e na área tecnológica ou do conhecimento em que se dão os projetos.

Esses fatores e todo o processo relacionado a eles são definidos como sendo muito dependentes de uma liderança que valorize as pessoas e propicie um ambiente criativo, ou seja, um clima empresarial propício à inovação. Tal ambiente se caracteriza pela descentralização da liderança, pela confiança entre as pessoas, pelo espírito de equipe, pela boa comunicação interna, pela definição clara de papéis e de responsabilidades de cada colaborador pela política de aceitação de erros e de incentivo à experimentação.

Considerando-se a relação direta encontrada entre a capacidade de liderança e o sucesso da inovação na empresa, organizou-se, no Quadro 2, um código de conduta do empreendedor inovador, daquele que consegue um bom desempenho em sua empresa, mesmo com as adversidades externas, e na Figura 4, a importância relativa dos fatores que impactam positivamente sobre o processo de inovação, no que se refere às atitudes/contextos relacionados ao empreendedor da MPE.

Voltando o olhar observador mais especificamente para o perfil da liderança, novamente a importância da capacitação aparece como um dos fatores primordiais da conduta do empreendedor inovador. 0 líder da empresa inovadora é muito comprometido com seu negócio, tem interesse em sua empresa e em tudo que a envolve e constantemente repensa a empresa por meio de sua própria capacitação.

Este líder busca atualização constante sobre seu negócio, seu produto/diferencial, o mercado e seus clientes, por meio de investimentos em pesquisas, frequentes análises de mercado, conectando-se a seus clientes, contratando consultorias para melhorar partes da gestão da empresa quando necessário, frequentando ambientes inovadores, participando de eventos da área de atuação e realizando cursos. 
Quadro 2 - Principais requisitos-chave do empreendedor inovador segundo a análise

\begin{tabular}{|c|l|}
\hline \multicolumn{1}{|c|}{$\begin{array}{c}\text { Valoriza o } \\
\text { conhecimento }\end{array}$} & $\begin{array}{l}\text { Qualificado, busca constantemente seu desenvolvimento por meio de treinamento e atualização } \\
\text { sobre o próprio negócio. Também promove a capacitação dos colaboradores e busca apoio de } \\
\text { parceiros e do governo. }\end{array}$ \\
\hline $\begin{array}{c}\text { Valoriza as pessoas } \\
\text { e suas perspectivas } \\
\text { do negócio }\end{array}$ & $\begin{array}{l}\text { Incentiva e cria meios para a realização do trabalho em equipe, comprometendo a todos com as } \\
\text { melhorias constantes, estimulando-os a trazer soluções. Flexível, empático e receptivo a novas } \\
\text { ideias e a diferentes pontos de vista. Sempre procura por novas conexões: tem uma boa rede } \\
\text { de relacionamento, faz parcerias e procura satisfazer o cliente. }\end{array}$ \\
\hline $\begin{array}{c}\text { Possui visão } \\
\text { sistêmica e } \\
\text { estratégica }\end{array}$ & $\begin{array}{l}\text { Preza por um ambiente organizado, determina metas e busca atingi-las. Assim, realiza um bom } \\
\text { planejamento antes de implementações, analisando e minimizando riscos. Investe em gestão } \\
\text { empresarial e sua empresa possui gestão adequada em todas as áreas, incluindo gestão de } \\
\text { resultados e indicadores para, inclusive, prognosticar o futuro do negócio. }\end{array}$ \\
\hline $\begin{array}{c}\text { É ousado e gosta de } \\
\text { inovar }\end{array}$ & $\begin{array}{l}\text { É reativo às novas tendências de seu mercado e sabe que o sucesso muitas vezes é atrelado } \\
\text { ao risco ou à mudança. Sua confiança é pautada no conhecimento e na análise de risco. Por } \\
\text { isso, não tem medo de errar, de experimentar e aceita melhor os erros das pessoas envolvidas } \\
\text { no processo de inovação. Tem certa agressividade comercial, pois é ambicioso, determinado e } \\
\text { competitivo. }\end{array}$ \\
\hline
\end{tabular}

Fonte: Elaboração e organização da autora (2017).

Outra peculiaridade que se sobressai no líder inovador é a de ser um bom ouvinte. Este traço de personalidade, comum no empreendedor de sucesso, comum na liderança que engaja e inspira as pessoas à sua volta, muitas vezes é raro na grande maioria das pessoas, no exercício de suas atividades de trabalho. Geralmente as pessoas têm muita dificuldade em ouvir plenamente, utilizando-se de preconceitos e indo direto às conclusões, ou avaliando situações de forma bastante rasa, sem considerar os diversos pontos de vista que poderiam enriquecer análises de situações complexas.

Entretanto, o líder que se volta para o processo de inovação e que consegue atingir bons resultados em sua empresa sabe ouvir seus colaboradores, clientes, fornecedores, outros empresários e parceiros, de modo a pensar sobre o mesmo problema de formas diferentes, não necessariamente concordando, mas melhorando sua perspectiva. Desta maneira, envolve a todos em um bom ambiente de trabalho, de confiança e criatividade, no qual exerce proatividade, dedicação efetivamente comprometida, demonstrando vontade de fazer acontecer, disposição e disponibilidade.

Além disso, a análise caracteriza o líder como sendo descentralizador, delegando atividades e definindo responsabilidades para as funções, destinando menos de seu tempo para o operacional e mais para pensar estratégias e para planejar. Disciplinado e estrategista, realiza acompanhamento de ações, mensuração e análises de resultados e de informações pertinentes ao negócio, que entende como um sistema.

Uma visão sistêmica do negócio ocorre quando o empresário entende que cada parte da empresa e dos negócios funciona de forma interdependente para compor uma totalidade maior, considerando-se os assuntos internos (gestão, pessoas, processos, etc.) e externos da empresa (mercado, clientes, concorrentes, parceiros, etc.). É preciso, portanto, compreender cada parte dessa totalidade e as ligações de cada parte entre si, ou seja, o funcionamento deste todo, de modo a ter uma visão analítica (quando se compreende cada parte) e sistêmica (quando se compreende a totalidade da empresa e do mercado onde se insere). Quando se tem essa compreensão de como sua realidade funciona, fica muito mais fácil avaliar, propor projetos, realizar os planejamentos e os acompanhamentos necessários. 
Figura 4 - Importância relativa dos fatores que caracterizam o empreendedor inovador

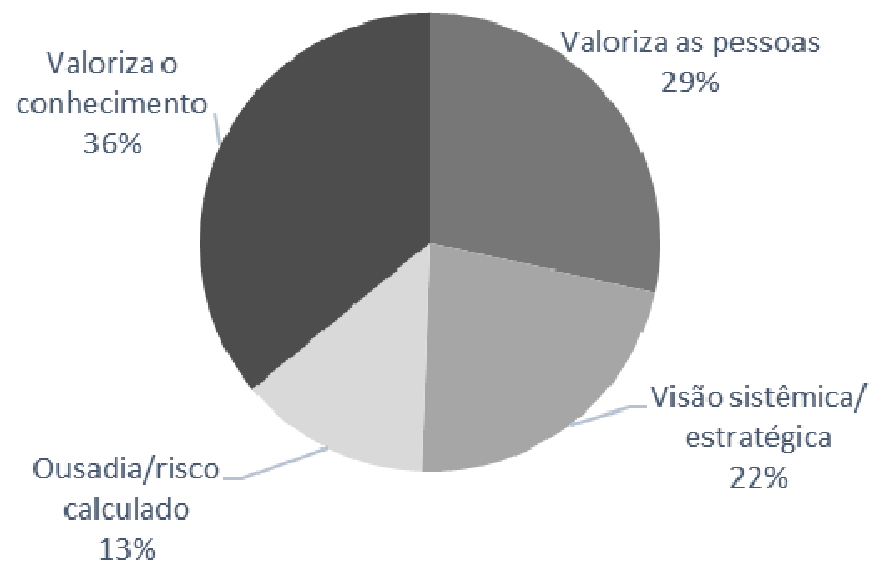

Fonte: Elaboração e organização da autora (2017)

Essas características também exprimem outros traços do perfil do líder da empresa inovadora: dinâmico, tem energia e profundo comprometimento. Por ser curioso e focado na inovação, acaba sendo criativo, possuindo uma mente inovadora, buscando melhorar sempre, de forma metódica, inclusive almejando seu desenvolvimento pessoal, tornando-se uma pessoa consciente e observadora, flexível, adaptativa e resiliente.

Outra peculiaridade do empreendedor inovador se relaciona à coragem, pois não tem medo de arriscarse. Mas esta segurança em experimentar, em investir em algo novo é totalmente pautada no conhecimento, mesmo que parcial. Sente-se muito mais seguro quem mensura o risco, mesmo que seja uma tentativa arrojada. Para inovar é preciso assumir riscos, investir, às vezes, apenas com longo prazo de retorno, assim como é imperativo tolerar erros, porque a inovação demanda experiências e novos aprendizados. Deste modo, 0 empreendedor inovador reconhece seus erros, e tem mais flexibilidade com os erros de seus colaboradores e de sua empresa.

\subsection{Fatores que Funcionam como Barreiras à Inovação nas MPE}

A experiência prática diz que as inovações apresentam vulnerabilidade em MPE, devido a situações comumente presentes, como a ineficiência da gestão, a falta de mão de obra qualificada, principalmente no nível de gerência, a falta ou o uso incorreto de recursos financeiros e a escassez de talentos criativos, diminuindo as chances de prosperarem. Outro fator apontado como dificultador é a gestão geralmente centralizada na figura do próprio empreendedor, que normalmente não reconhece as práticas de um bom gerenciamento, sendo suas ações intuitivas e desorganizadas.

Alguns empresários não veem a importância do planejamento de suas ações, da disciplina e da organização de suas empresas, do estabelecimento de regras na gestão, do esclarecimento e da objetivação dos procedimentos de trabalho, com determinação dos responsáveis por cada área e atividade. Alguns empresários das MPE nem ao menos conseguem identificar as falhas existentes na gestão, devido à falta de capacitação.

Entretanto, uma boa gestão se constitui em uma base sólida para a inovação e a desorganização, a falta de gestão do tempo, a gestão deficiente em áreas da empresa, como em finanças, com falta de controles financeiros, ou marketing inadequado, sem pesquisa de mercado, por exemplo, são fatores que competem com a inovação. Além disso, a falta de visão da liderança, com a centralização das decisões e/ou atividades operacionais na figura do gestor, leva ao excesso de trabalho operacional e minimizam seu tempo para investir em uma percepção mais ampla, do sistema maior onde se insere a empresa, limitando sua visão estratégica e de futuro. 
Assim, no Quadro 3, estão expostos os principais fatores que concorrem com a inovação nas MPE e na Figura 5 a importância relativa desses fatores.

Quadro 3 - Principais fatores que contribuem para impedir a inovação nas MPE segundo a análise proposta

\begin{tabular}{|l|l|}
\hline \multicolumn{2}{|c|}{ Fatores que competem com a inovação em MPE } \\
\hline $\begin{array}{l}\text { Gestão inadequada } \\
\text { da empresa e da } \\
\text { equipe }\end{array}$ & $\begin{array}{l}\text { A centralização das decisões e/ou atividades operacionais na figura do gestor limitam sua } \\
\text { visão estratégica e de conjunto da empresa, minimizando sua capacidade de investir em } \\
\text { conhecimento e inovação. A desorganização da empresa e a gestão deficiente geram um } \\
\text { ambiente de desmotivação e desorientação, inapropriado para implantações de quaisquer } \\
\text { projetos que necessitem de acompanhamento. }\end{array}$ \\
\hline $\begin{array}{l}\text { Comodismol } \\
\text { desatualização }\end{array}$ & $\begin{array}{l}\text { Caracteriza-se pela imobilidade e pelo isolamento da empresa, ao ter resistência às } \\
\text { mudanças. Esta inércia também se define pela desmotivação e desinteresse pelo aprendizado, } \\
\text { levando ao desconhecimento do mercado e sobre como inovar para ter mais competitividade. }\end{array}$ \\
\hline $\begin{array}{l}\text { Limitação (ou } \\
\text { aparente limitação) } \\
\text { de recursos }\end{array}$ & $\begin{array}{l}\text { Pode haver falta de recursos humanos, financeiros ou de tempo para a implantação de } \\
\text { inovações, ou ocorrer dificuldades operacionais nas implantações. Pode haver insegurança no } \\
\text { investimento, incerteza do risco representado, e do prejuízo atrelado ao risco. Por vezes, não } \\
\text { há falta de recursos, exatamente, ou de conhecimento, mas não são bem administrados. } \\
\text { Essas limitações, em geral, podem ser equalizadas pela capacitação e pelo estabelecimento } \\
\text { de parcerias, além do apoio de profissionais da área de gestão. }\end{array}$ \\
\hline
\end{tabular}

Fonte: Elaboração e organização da autora (2017)

Figura 5 - Importância relativa dos fatores que impedem a inovação empresarial

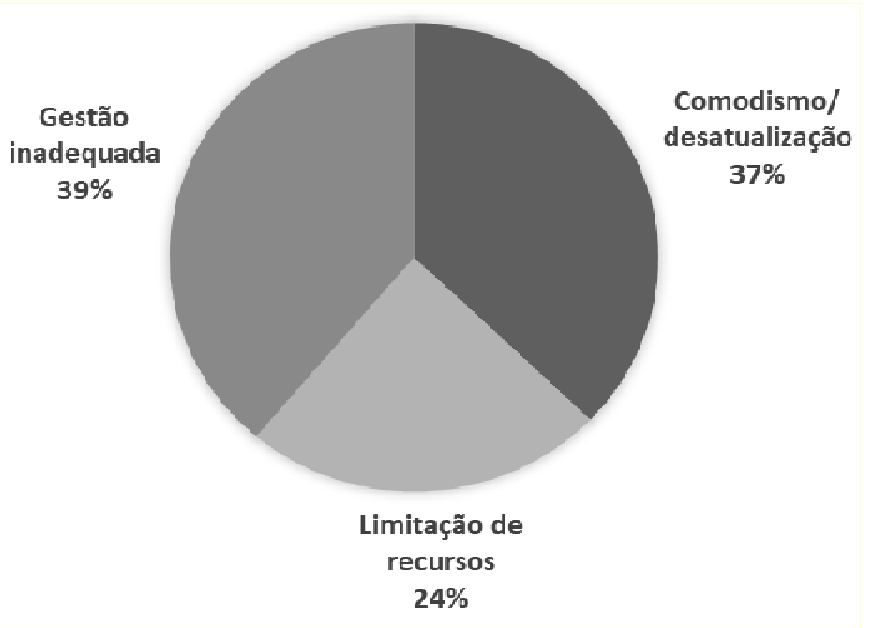

Fonte: Elaboração e organização da autora (2017).

Ainda, a pessoa que está na gestão inadequada de uma empresa pode apresentar um discurso vitimador, passivo e intolerante, buscando culpados (geralmente os colaboradores), em um ambiente em que falta sinergia, cuja equipe é desmotivada.

Outro fator que prejudica a inovação, o comodismo, caracteriza-se pela privação de contado com situações/locais inovadores, ou mesmo, pelo desvio proposital de situações de aprendizagem e mudança. 0 comodismo é outra definição para desatualização, representando a falta de conhecimento técnico, a ausência de pesquisas mais aprofundadas sobre os assuntos de interesse da empresa, como as de mercado e sobre a 
concorrência. $\mathrm{O}$ comodismo, adicionado à falta de gestão adequada do tempo, leva à procrastinação. Também leva a preconceitos, por exemplo, que inovação sempre custa muito caro e não tem retorno financeiro.

\subsection{Influência do Programa Ali na Inovação das MPE Acompanhadas}

De acordo com uma síntese da percepção dos agentes locais de inovação, a influência do Programa ALI na promoção da inovação nas MPE ocorre com o aporte ao conhecimento do empreendedor, aumentando suas perspectivas e levando novos métodos para inovar, ativando-o a iniciar, planejar e se manter no processo de inovação, auxiliando-o nas tomadas de decisão e contribuindo com a cultura da mudança, sobretudo por meio da melhoria ou consolidação da gestão empresarial, favorecendo, também, a ampliação da consciência/percepção do negócio pelo empreendedor. Assim, quando os resultados das ações inovadoras começam a aparecer, o empresário se sente motivado e se torna mais dedicado, e um ambiente inovador tende a se fortalecer progressivamente.

\section{CONSIDERAÇÕES FINAIS}

Os primeiros passos em direção à inovação e ao sucesso das MPE são sempre relacionados ao conhecimento: compreender o que é inovação, o próprio negócio, sua a posição no mercado, os clientes, capacitar a liderança e investir na capacitação da equipe. Em seguida, e não menos importante, requer-se ir além e efetivamente fomentar a cultura de inovação na empresa, envolvendo a todos e realizando levantamentos periódicos de oportunidades de melhoria, estabelecendo projetos para inovação, de forma planejada, com avaliação dos riscos, realização de testes e acompanhamento de indicadores de resultados. Demanda planejar as ações cotidianas, em um ambiente organizado, bem como as ações voltadas à inovação, realizando projeções futuras.

Portanto se requer o processo de organização da empresa por meio da consolidação de uma gestão profissional, com formalização e documentação de procedimentos e determinação clara de papéis, acompanhada por uma gestão de pessoas para além de ser considerada adequada, comprometida e qualificada, mas também inspiradora, motivadora, aberta a sugestões de funcionários, fornecedores, clientes, parceiros, consultores e de outros empresários. Desta maneira, torna-se essencial envolver a equipe na realização das mudanças necessárias, engajando todos os colaboradores e definindo responsabilidades, sem centrar no empreendedor a execução de atividades operacionais e a tomada de todas as decisões, ampliando, assim, o espaço de atuação dos colaboradores nos processos criativos e inovativos.

\section{REFERÊNCIAS}

ALEXANDRE, M. M.; SILVA FILHO, J. C. L. da. Obstáculos à inovação na indústria brasileira: uma análise setorial. In: Simpósio de Administração da Produção, Logística e Operações Internacionais. Anais. São Paulo: FGV - Fundação Getúlio Vargas, ago.2014.

BACHMANN, D. L.; DESTEFANI, J. H. Metodologia para estimar o grau de inovação nas MPE: cultura do empreendedorismo e inovação. Curitiba: Bachmann \& Associados, 2008. 17 p.

BRASIL. República Federativa. Estatuto Nacional da Microempresa e da Empresa de Pequeno Porte. In: Lei Complementar 123, de 14 de dezembro de 2006 . Disponível: http://www.planalto.gov.br/ccivil_03/leis/LCP/Lcp123.htm. Acesso: 05.out.2017.

BROWN, S. Innovation and evolution in UK retailing: the retail warehouse. European Journal of Marketing, v. 24, n. 9, p. 39-54, 1990.

CARLOMAGNO, M.; SCHERER, F. Gestão da Inovação na Prática: como aplicar conceitos e ferramentas para alavancar a inovação. 2. ed. São Paulo: Atlas, 2016. 320 p.

CNPq - Conselho Nacional de Desenvolvimento Científico e Tecnológico. ALI - Agentes Locais de Inovação. Disponivel em: http://cnpq.br/apresentacao-ali. Acessado em: 03.out.2017.

FNQ - Fundação Nacional da Qualidade. Modelo de Excelência em Gestão. 2014. 18 f. 
GALLI, S.; TORREGGIANI, S. La gestione dell'innovazione nelle piccole e medie imprese: Strumenti e metodi per innovare processi, prodotti e servizi. Milano: Franco Angeli. 2006. 224 p.

IBGE - Instituto Brasileiro de Geografia e Estatística. Cidades. 2010-2014. 2014. Disponível: https:/l cidades.ibge.gov.br/v4/brasil/sp/sao-paulo/panorama. Acesso: 14.jul.2017.

IBGE - Instituto Brasileiro de Geografia e Estatística. Pesquisa de Inovação 2014. Rio de Janeiro: IBGE, 2016, $105 \mathrm{f}$.

JIMÉNEZ-JIMÉNEZ, D.; SANZ VALLE, R. Innovation, organizational learning, and performance. Journal of Business Research, v. 64, n. 4, p. 408-417, april 2011.

KUHL, M. R.; CUNHA, J. C. Obstáculos à implementação de inovações no Brasil: como diferentes empresas percebem sua importância. Brazilian Business Review. v. 10, n. 2, p. 1-25, 2013.

MACHADO, D. D. P. N. Organizações inovadoras: estudo dos fatores que formam o ambiente inovador. RAI Revista de Administração e Inovação. FGV - Fundação Getúlio Vargas: São Paulo, v. 4., n. 2, p. 5-28, 2007.

MÜCELDILI, B.; TURAN, H.; ERDIL, O. The influence of authentic leadership on creativity and innovativeness. Procedia-Social and Behavioral Sciences, 99: 673-681, 2013.

NEUMARK, D.; WALL, B.; ZHANG, J. Do Small Businesses Create More Jobs? New Evidence for the United States from the National Establishment Time Series. The Review of Economics and Statistics, v. 93, n. 1, p. 16-29, February 2011.

OECD - Organization for Economic Co-Operation and Development \& EUROSTAT - Statistical Office of the European Communities. Oslo Manual: guidelines for collecting and interpreting innovation data. 3th. ed. The Measurement of Scientific and Technological Activities. Oslo: OECD/Eurostat, 2005. 163 p.

OIT - Organização Internacional do Trabalho. Panorama Temático Laboral - Pequeñas empresas, grandes brechas: Empleo y condiciones de trabajo em las MYPE de America Latina y el Caribe. Lima: Oficina Regional para America Latina y el Caribe. Organización Internacional del Trabajo. Vol. 2. Junho de 2015. 72 p.

OKE, A.; MUNSHI, N.; WALUMBWA, F. O. The Influence of Leadership on Innovation Processes and Activities. Organizational Dynamics, v. 38, n. 1, p. 64-72, 2009.

SAWHNEY, M.; WOLCOTT, R. C.; ARRONIZ, I. The 12 different ways for companies to innovate. MIT Sloan Management Review, v. 47, n. 3, p. 75, 2006.

SEBRAE - Serviço Brasileiro de Apoio às Micro e Pequenas Empresas. Estudos regionais por escritórios regionais. In: Estudos de mercado. Maio de 2012.2 Disponível: http://www.sebrae.com.br/sites/PortalSebrae/ufs/sp/sebraeaz/estudos-regionais, 735bdc0944358510VgnVCM1000004c002 10aRCRD. 2012. Acesso: 14.jul.2017.

SEBRAE - Serviço Brasileiro de Apoio às Micro e Pequenas Empresas. Programa ALI: Material de Estudo: Prospecção e negociação; Inovação e gestão na empresa de pequeno porte; Diagnóstico e plano de ação; Atividades e procedimentos operacionais do ALI. 2015. (Apostila de Treinamento, disponibilidade restrita). Brasilia: SEBRAE, 2015.

SEBRAE - Serviço Brasileiro de Apoio às Micro e Pequenas Empresas. Sobrevivência das empresas no Brasil. Marco Aurélio Bedê (Coord.). Brasília: SEBRAE. 2016. 96 p.

SEBRAE - Serviço Brasileiro de Apoio às Micro e Pequenas Empresas. O Projeto. In: ALI - Agentes Locais de Inovação. 06 de fevereiro de 2017.2 Disponível: http://app.pr.sebrae.com.br/ali/Conteudo.do?codConteudo=2083\&codMenuAtivo=709. 2017. Acesso: 03.out.2017.

SEBRAE-PR - Serviço Brasileiro de Apoio às Micro e Pequenas Empresas do Paraná. Guia para a Inovação: Instrumento de orientação de ações para a melhoria das dimensões da Inovação. Curitiba: SEBRAE-PR. 2010. $116 \mathrm{p}$.

SEBRAE-PR - Serviço Brasileiro de Apoio às Micro e Pequenas Empresas do Paraná. Guia para a inovação: instrumento para a melhoria das dimensões da Inovação. 2ª ${ }^{\mathrm{a}}$ ed. Curitiba: SEBRAE-PR, 2015. 186 p. 
SEBRAE-SP - Serviço Brasileiro de Apoio às Micro e Pequenas Empresas de São Paulo. Inovação e Competitividade das MPE Paulistas. SEBRAE, 2008. 20 p.

STOREY, D. J. Understanding the small business sector. London/New York: Routeledge, 2016. 346 p.

WALUMBWA F. O., AVOLIO B. J., GARDNER W. L., WERNSING T. S. and S. J. PETERSON. Authentic Leadership: Development and Validation of a Theory-Based Measure. Journal of Management 34: 89, 2008.

NOTA EXPLICATIVA: Trabalho realizado para o Serviço Brasileiro de Apoio às Micro e Pequenas Empresas (SEBRAE), com bolsa de extensão no país do Conselho Nacional de Desenvolvimento Científico e Tecnológico (CNPq). Agradecimentos aos agentes do Programa ALI. 